\title{
Perception of academic learning environments and perceived impact on articulation of employability skills: a mixed methods study
}

\author{
Dr Catherine Hayes \\ John Fulton \\ Siobhan Devlin \\ Diane Westwood \\ lain Garfield \\ Phil Beardmore \\ David Archer \\ Michael Collins \\ Lewis Bingle \\ University of Sunderland, UK
}

\section{Abstract}

This study reports on the findings of a mixed methods study that was undertaken to establish student perceptions of academic learning environments and the perceived impact of these on their articulation of employability skills. This was so student perspectives on employability could be used to inform reflection on pedagogic practices for their educators in higher education. Using a purposive sample of 250 students based in a recently modernised Sciences Complex Building in a Higher Education Institution (HEI), the study was cross sectional and descriptive by design. The social learning spaces researched were perceived by participants to provide optimal academic learning environments for their development of knowledge, skills and professionalism through certain signature pedagogies as they progressed through their programmes of study. Students also expressed the view that their acquisition of functional skills were significantly more important than any personal attributes/characteristics that they brought to programmes. What also mattered was whether the importance of certain graduate skills to the workplace had been made explicit to them so that they could see the relevance of their studies to practice. In defining 'graduateness', in employability terms the research 
concluded that it was necessary to consider how it was shaped by the context of delivery of subject disciplines, stages of academic progression, and the use of social learning spaces, as they all had a significant impact on the perceptions students held about their potential employability upon completion of their academic programmes.

Keywords: learning environments; employability; signature pedagogies; situated cognition; problem based learning.

\section{Introduction}

Situated cognition is the theory that proposes knowledge can be framed by practical applications to practice (Wellington, 2015). It can be argued that situated cognition is pivotal to understanding not only how students acquire knowledge and skills, but also how they then perceive them and articulate those skills to potential employers - this has been termed 'vocational credibility' (Dacre Pool et al., 2014). Physical academic learning environments are of direct relevance therefore to situated cognition because they help organise not just how students learn, but how they might transfer their knowledge to the workplace (Senior et al., 2014). Student perceptions of the impact of physical learning environments are relevant in three respects:

1. How they link the context of their learning to the workplace will determine how they view its relevance to practice.

2. How students articulate their 'graduateness' or employability to an employer will impact on how equipped they are for work.

3. Preparing students to articulate their employability will impact on their ability to impress potential employees if they are shortlisted for job interviews (Mahmood et al., 2014).

The aim of this research was to give educational providers in the research setting a means of reflecting on the extent to which students felt that their learning environment (the recently modernised 'Sciences Complex Building') helped develop or foster generic employability skills. This was to ensure that the institution could use the information gathered to better equip students to understand not only the relevance of what they learned and how they learned it, but how it might be relevant to their future employability. 
More importantly, the research asked how students could be equipped to articulate this understanding to potential employers through changes in the curricula and pedagogies they were exposed to (Freeman et al., 2014).

The Sciences Complex at the university has been designed and developed to accommodate Social Constructivist approaches to learning (Vygotsky, 1978). Moves towards Problem Based Learning (PBL) / Inquiry Based Learning (IBL) have necessitated consideration of learning spaces and how best student participation, in terms of active involvement in the creation of knowledge, can best be facilitated. In small enough cohorts, purist PBL has been delivered successfully, with various initiatives to incorporate hybrid models of PBL in practice (Hayes and Davies, 2014). With much larger cohorts, where it would be a physical impossibility to engage groups of 8-10 in purist PBL, there has still been an emphasis from academic development initiatives across the Faculty of Applied Science to use inquiry based approaches which afford students more than traditional didactic teaching methodologies.

\section{Articulating employability through the acknowledgement of authentic learning environments}

The consideration of how students articulate their potential employability is not a new phenomenon. A plethora of studies have considered the need of Higher Education Institutions (HEIs) to address the capacity of students to focus on their potential employability, and explore how they might enact their employability, for example, in job interviews (Pegg et al., 2012; Herrington et al., 2014). In addition, the question of whether undergraduate students acknowledge how physical learning environments facilitate the acquisition of these employment skills has been the source of some contention and debate (Sharples et al., 2014).

Ensuring that teaching methodologies and all pedagogic practice is framed within an authentic learning environment is one mechanism of providing students with an insight into the world of work. However, the notion of situated cognition, discussed above, is not often acknowledged beyond the context of placement provision, unless the prospect of modernising buildings' infrastructure becomes an issue for HEls (Salmon and Wright, 2014). The phrase 'the missing perspective', coined by Tymon (2013), points to the 
relatively blinkered attitude most students take towards not only what knowledge is, but how it works in practice and, more specifically in the context of this paper, how the infrastructure of buildings, fixtures and fittings can contextualise and frame teaching methodologies (Thomas and Anderson, 2014). Taking this into account means that one can begin to visualise how learning environments might shape educational experience and influence future potential employability skills. The seminal work of Entwistle and Ramsden (2015), now revived for the $21^{\text {st }}$ Century, framed how academic learning environments could provide a means of shaping the characteristics of graduates in educational institutions over thirty years ago. In the current political climate of workforce development, as employability is one of the key focal points of higher education pedagogy and innovation, it remains important to ask if this is still the case (Hordern, 2014).

\section{Methods}

The study was acknowledged and designed as a relatively small scale study at a post1992 university. From this perspective, no claim of generalisability is made from the study to a wider context. The methodological approach adopted was selected for two main reasons:

1. The approach offered the highest degrees of procedural trustworthiness and authenticity in relation to the data collected in both phases of the research.

2. In comparison to observational and longitudinal studies, it offered a very practical and straightforward means of data collection and analysis in the context of a busy Sciences Complex building.

The research had two distinct phases, in keeping with the mixed methods approach adopted; each is outlined below.

\section{Research phase one}

Following formal institutional ethical approval for both phases of the research study, students of the Faculty of Applied Sciences in the Departments of Pharmacy Health and Wellbeing and Sport and Exercise Sciences were recruited purposively to the investigation. This sampling technique was adopted on the basis that students undertaking 
programmes delivered by the Faculty of Applied Sciences were most able to answer questions about the learning environment that the Sciences Complex building offered. The process of participation was voluntary and students were invited to participate via posters and the availability of questionnaires, which led to a high response rate. The sample was made up of 250 students entering Semester Two of their studies in the academic year 2014-2015. No specific numbers of students from each specific stage of their studies were selected as the researchers had to be opportunistic in being able to access subjects. The study was cross sectional and descriptive in design, with data collected via a specifically adapted version of the Clinical Learning Environment Inventory (CLEI), which was originally designed to capture student perceptions of their psychosocial learning environments (Chan, 2003; Pololi and Price, 2000). The adaptations captured student perceptions about the extent to which learning environments prepared students in terms of graduate employability, regardless of their disciplinary background in the Faculty. The questionnaire consisted of 15 questions which asked students to respond with an opinion as to whether they agreed with the level to which the physical learning environments in the Sciences Complex building had impacted on the quality of their student experience, either less than expected, as expected, more than expected, or consistently more than expected. These values were correlated with the dimensions seminally outlined by Moos (1980) and mapped against 15 core skills in relation to:

- Individualisation - the degree of autonomy that students are afforded in relation to their decision-making skills.

- Innovation - the degree to which new approaches to teaching methodologies can be implemented.

- Involvement - how much students actually contribute to activity in the learning environment.

- Personalisation - how much of an opportunity each student is afforded in interacting with their teacher or facilitator of learning.

- Task Orientation - how clear and well organised organisational activities are.

- Satisfaction - the degree to which personal and professional development are taking place.

The 15 core skills, which were developed from and overarched Moos' dimensions, became the focus of the study. Student perceptions of each were gathered to illuminate the extent 
to which students felt that their learning environments, namely the Sciences Complex, had impacted on the development of their:

- Communication Skills

- Confidence

- Independence / Capacity to Learn Autonomously

- Research Skills

- Teamwork

- Leadership

- Reflection

- Active Listening Skills

- Creativity

- Clinical Decision-Making

- Initiative

- I.T. Skills

- Professionalism

- Classroom Management

- Self-Esteem

A total of 212 usable responses (response rate $85 \%$ ) were obtained, comprising 74 Sport and Exercise degree students (35\%), 89 (42\%) Pharmacy degree students, 27 (13\%) Biomedical Sciences degree students, and $22(10 \%)$ were Nursing top-up degree students.

\section{Research phase two}

Semi-structured interviewing of 10 voluntary respondents from the students who had taken part in the questionnaire was conducted to further explore the individual experiences students had of academic learning environments at the university. In order to ensure completely random representation of students from across the faculty, a poster inviting student participation in the study was displayed in the main entrance hall of the university. All participants were given pseudonyms to minimise the potential for their identification, (Lahman et al., 2015), however, pen portraits (biographical narratives provided by the students) were constructed to facilitate meaning-making of their perceptions (La Placa et 
al., 2014). This was incorporated as giving a higher degree of contextual significance to the commentaries of students in terms of the representation of their perceptions. It aided the researchers in framing meaning in context and culture, not just through a series of decontextualised transcriptions.

\section{Data analysis}

Braun and Clarke's (2006) six phase approach to thematic analysis was adopted as a systematic, yet recursive, approach to inductive qualitative analysis. In accordance with recommendations of the process, data was not viewed in a linear fashion and ideas were extracted as they emerged during the process of interpretation (often after visiting and revisiting particular transcripts), and the researchers proceeded to the next phase where appropriate.

\section{Phase one}

This entailed familiarisation with the data set where the researchers immersed themselves in the data collected via extensive reading and re-reading of the transcribed information from the data collection. This was a process undertaken by two researchers where a consensus could be reached between those themes independently found to be most commonly occurring.

\section{Phase two}

Data was coded: this involved creating and identifying themes that came from analysis of the data sets. This subsequently guided analysis and provided a systematic approach at a semantic and conceptual level, which could be mapped against extant published literature. This was achieved by manually coding every data item and completed by the two researchers involved, collating every element together so that it could be independently checked for inclusion in the overall findings by both. 


\section{Phase three}

This entailed exploring the data for the specific themes identified in Phase Two of the data analysis, defined in accordance with Braun and Clark (2006, pp. 57-59) as 'coherent and meaningful patterns in the data' of direct relevance to the research aim. If a theme emerged from more than $10 \%$ of respondents, it was deemed to be meaningful to the study. Its coherence was judged on the basis of non-ambiguous articulation of student perceptions. Since there was a degree of diversity in the questions asked, this meant that $100 \%$ of respondents contributed to at least four themes.

\section{Phase four}

This stage involved reviewing the emergent themes. It provides a means of checking that these were relevant to the data extracts when they are taken in abstraction from the complete data set.

\section{Phase five}

Providing a definitive theme for each one that has emerged from the study entails defining the overall findings so that each can be individually examined.

\section{Phase six}

Analysing the themes relative to one another in terms of their rate of occurrence and writing up the findings in relation to this. This involved merging analytical narratives and examining this in relation to the existing published evidence base.

\section{Findings and discussion}

The research with Faculty of Applied Sciences students provided some useful insights from a range of students who commented on how the research setting's learning environments had facilitated their acquisition of generic and transferrable employability skills. The three most salient findings of the study of their perceptions revealed: 


\section{Signature pedagogies across the Faculty of Applied Sciences have an impact on the perceived development of employability skills}

The designation of space at the setting is not overly prescriptive in terms of availability and staff can easily adapt rooms, as furniture has not been fixed in position, to accommodate a wide variety of teaching and learning methodologies. In terms of the diversity of programmes offered across the Faculty, one of the greatest challenges is to provide generic teaching and learning environments that are not specifically owned or characterised by one subject discipline. The obvious exception to this is where space has been designated for very specific purposes, like chemistry laboratories, and in areas for subject specific instrumentation, such as the gait analysis equipment used in the Department of Sport and Exercise Science. What also became apparent through the analysis of findings was the clear development of personal learning identities and the shaping of these into the social identities that distinguished individual professional disciplines. The distinction made by the students between personal attributes (such as self-esteem, confidence, professionalism and initiative), and the functional attributes of IT Skills, classroom management, clinical decision-making, teamwork, and leadership, was significant. It was evident that there were instances where students appeared to value functional skill over professional capability. For example, students in core laboratory sciences were less concerned about notions of professionalism than the psychomotor skills required to undertake their roles effectively. The following quotes illustrate this clearly:

I'm a pretty sociable person but I'm not that bothered about the soft side of things but I need to know things are bang on for accuracy, so I look for great labs and the best equipment to get the job done - beyond that I'm not too bothered. (Student A)

I'm about 'doing' which is hands on, get it done and no flannel sort of person - I don't need to learn much more than the hands on mechanics of being able to do the job properly - the rooms here let me do that and I'm not much of a socialiser anyway. (Student B)

This was a stark contrast to students who will be working at the front line of health care provision in the NHS, who valued their ability to be professional above almost everything they did: 
These buildings, well you can tell they're newly renovated because they look so modern - they make it seem real for me because I can really stretch myself in terms of preparing for practice and I can feel secure knowing that I'm not going to hurt people as I'm learning but reassured that I'm learning enough so that when I get out onto placement in the real world, I really know what l'm doing. (Student C)

It's not just about the buildings it's about the fact that if we can use them then people we work with (the patients, I mean) will still be benefiting from that 20, 30 or 40 years down the line - that's why it matters... people forget that sometimes. (Student D)

This is an interesting finding considering that from the published evidence base, employers place these skills of professionalism in exactly the polar opposite order of significance (Prendergast, 2015; Evetts, 2013). Since there is obviously a disconnect between what employers value and what the students in the study perceive to be most valued in the skills they leave university with, this finding is important. It emphasises the need for students to reflect on the expectations of potential employers so that they can value being able to demonstrate a balanced and objective consideration of how characteristics connected to employability might be articulated in future job interviews/applications etc. Additional support with this can also be provided within the institution with adjunct careers advice and support in relation to job interview preparations.

\section{Stage of student progression through programmes is significant in relation to the shaping of perceptions about the development of employability skills}

The research also showed that students' perceptions about employability clearly changed as students progressed through the stages of their respective programmes. In the earlier stages of study, students paid little or no attention to the notion of employability. This could be partly explained by the fact that a high proportion of participants were studying on vocational degree pathways, for example, qualifications like the MPharm or BSc (Hons) Nursing top-up degree, so they already knew what jobs they were going to be doing. The findings indicate that as educators we need to place significant emphasis on the need for students to articulate and express their experience and skills well to potential employers. Exactly how the influence of the perceived relationship that exists between academic learning environments and the concept of employability impacts on a student's capacity to articulate their available skills set at the point of a job interview is not addressed in this 
study. Those students who had a less clear future potential career pathway, for example the BSc (Hons) Public Health student cohort, needed support with being able to articulate how a generic degree pathway had sufficiently prepared them with the levels of critical thinking characterised by jobs in the public sector (Nagarajan and Edwards, 2015). Their comments on the perception of how they would use their degree to gain employment also highlighted their perceptions and their fears about where they would work and how they could best present themselves in an interview:

I've been here three years and I'm still not sure what l'll be doing at the end of the degree, there's like so many things I could do and it's hard to try and thing about how things in the modules will actually matter when it comes to getting a job... but I suppose they do when you think about it, just I think we don't think about it enough. (Student E)

I must admit l'm dreading the end of the course, not just in case I don't pass but in case I can't get a job because with this degree it's not like it leads to anything and the whole Uni has been geared to people who know what they're going to be doing at the end of their three years, so at least they've got a clue what an employer would want. (Student F)

This place is great but you've got to make the most of the opportunities you're given, some people don't use chances to volunteer or go along to anything beyond anything they absolutely have to... maybe they should be putting it all in the actual modules so that people see how relevant what their learning is. (Student G)

The seminal findings of Biggs (1985) and Ramsden (1991) are of significance to this study. Both contend that the articulation, or praxis orientation, of theoretical knowledge is shaped by learning environments and framed by students' individual levels of intrinsic motivation and basic expectations of the curricula with which they engaged thus leading to 'deeper' forms of learning. Deep learning leads to the capacity to use higher order thinking skills and is founded in process-based learning outcomes that afford students the opportunity to negotiate the complexities of the outcomes-based assessment methods which often characterise the kinds of inquiry-based learning provided by HEls (Jackson, 2015). For example, deep learning lies at the heart of the healthcare education agenda to engage healthcare professional students with higher order thinking skills and a capacity for critical 
reflexivity on practice (Mirghani et al., 2014). In relation to the linkage of learning to employability, deep learning can be regarded as important, particularly in relation to the capability of students' effective decision-making, communication and resilience.

\section{Social learning spaces are much appreciated as an adjunct to formal learning environments in the development of employability skills}

Participants who were interviewed admitted that until they were asked to comment on how academic learning environments impacted on the development of their employability skills, they had never consciously sought to look at the relationship between them. However, the Sciences Complex at the university has been designed and developed to accommodate Social Constructivist approaches to learning (Vygotsky, 1978). This approach ostensibly encourages students to use their interaction with one another and their external environment to construct meaning and then to develop that meaning into learning so that they can learn much from each other beyond the constraints of the academic curriculum. There was clear evidence that students related their capacity to perform functionally in higher education in relation to any prospective new role as a key indicator of whether they would be successful in their future job applications.

In the setting the majority of students valued the opportunity of having 'real world' experience in terms of work placement in order to develop these professional skills:

The Sciences Complex is great but however great it is it isn't the real world and so it can only give you so much that is real... but because that's put together with experience out there, well it's just been fantastic. (Student $\mathrm{H}$ )

The academic learning environments within which students worked were seen as pivotal to the development of notions of professionalism as this is what determined which teaching methodologies could be put into practice. Some key quotes on this issue included:

We've done a lot of PBL and it really gets you thinking. (Student I)

Most significantly, the space provided room for group-breakout sessions, social learning space, and the opportunity for flexible and adaptable rooms that could be adapted to fit the 
learning taking place. This is perhaps best illustrated by one student, who in the opportunity to provide qualitative feedback commentary wrote:

Just having the space to be and to know that being matters in relation to what you learn has been a real 'game changer' for me. It means that what you're learning has a context and it's alive. (Student $\mathrm{J}$ )

How inquiry-based learning was facilitated was seen as being greatly enhanced by the learning environments offered at the university, since they reflected not only a professional environment but also gave students the social space to reflect on learning in the affective domain. Several student commentaries reflected this:

The cases we did really opened my eyes; sometimes when you just look at the theory side of stuff it doesn't do you any favours because you lose sight of the real relevance of it... it's much better when you can apply it to something practical. (Student K)

I like the different rooms, it's really different to Sixth Form because there are specialist areas actually designed to fit around how you learn not just a bog standard classroom. (Student L)

Working in my module I did Lego and a metaphors project, and that sounds ridiculous really, which had nothing to do with the module title and l'd never have thought that could have relevance to the real world but it has changed my whole outlook on how I learn and how I will eventually teach - the surroundings here played a big part in making that happen. (Student M)

\section{Conclusion}

As acknowledged in the methodology section, this study also has limitations; it is a relatively small scale study at a post-1992 university. Whilst no allusion of generalisability is made from the study to a wider context, it does highlight the perceptions of a group of students who have considered, through their participant in this study, the learning environments on their employability skills. The study outlines the potential for more 
exploratory research to identify whether making clear to students the significance of their learning environments is actually important in terms of the perception of their student experience and their potential future employability. The outcome of this study suggests that where generic employability skills are embedded in programmes, this ought to be clearly communicated to students. This will ensure that students can recognise a) the contextual relevance of their learning to future employment settings and b) how the environment can support the development of desirable characteristics. Students ought to be made aware that learning spaces define and structure both their individual, professional and social identity, perhaps by incorporating an overview of this into their induction phase at the university. Perhaps the most salient of the findings of this study is the interrelationship of vocational credibility, signature pedagogy and generic skill. This overlap in the findings of the study provides the basis for an Employability Articulation Model (Figure A) which affords higher education the opportunity of contextually situating the acquisition of core skills, functionality and personal attributes in the culture and context of their individual institutions.

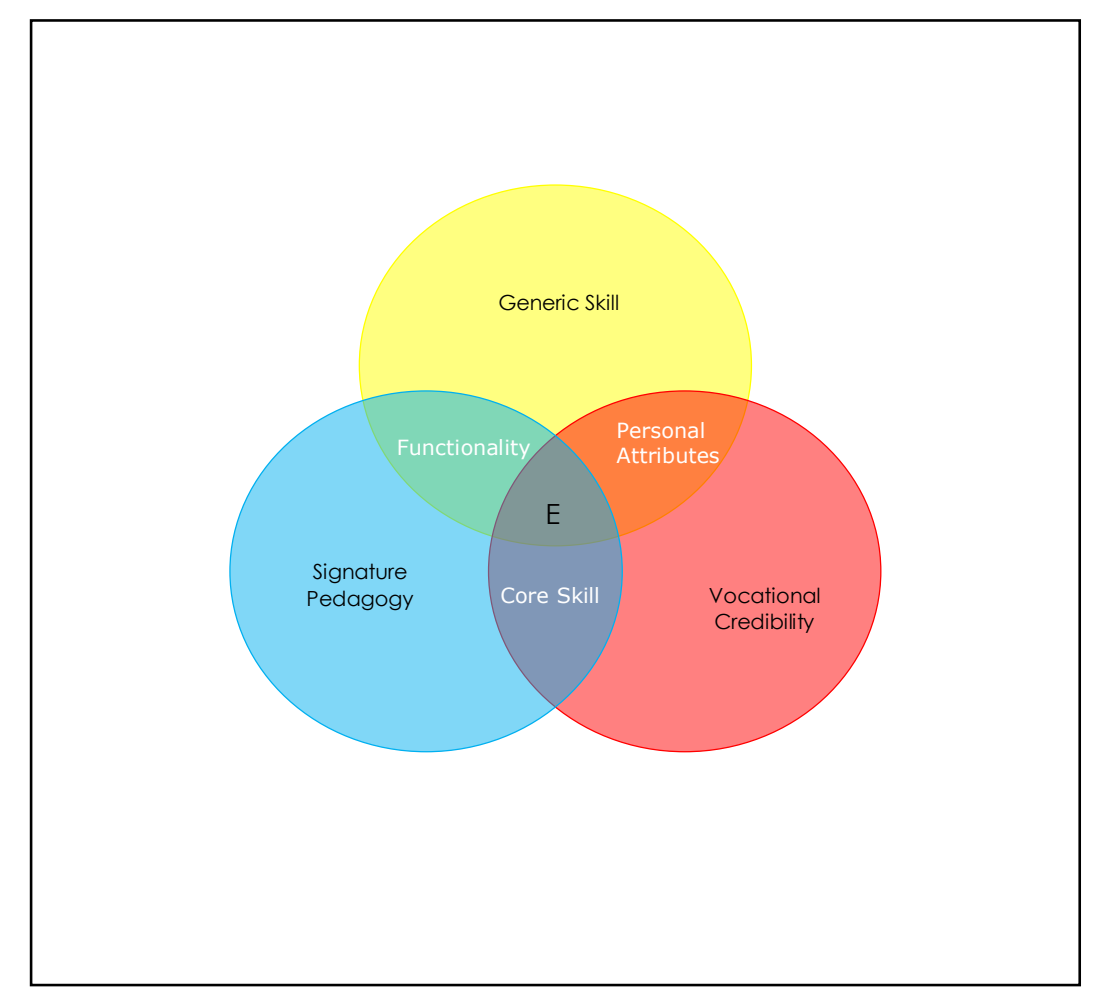

Figure A. Visual representation of the interrelationship between generic skill / vocational credibility and signature pedagogies: The Employability Articulation Model (E= Employability). 
This model permits a shared understanding of what the core term 'graduateness' might mean and how the articulation of 'employability' to students might be shared and disseminated across academic curricula by lecturers. The need for HEls to address the supply to the global economy of a new raft of employees on an annual basis is counterbalanced by the very great privilege they have in being transformative change agents. Their contribution to society generally, and the embedded contribution to shaping individual lives in particular, is one which transcends generations, raises aspiration and epitomises the philosophical essence of Western education.

\section{Acknowledgements}

The authors would like to thank all of the staff and students from the University of Sunderland who directly participated in this study and offered practical help in the organisation of the project.

\section{References}

Biggs, J.B. (1985) 'The role of metalearning in study processes', British Journal of Educational Psychology, 55(3), pp. 185-212.

Braun, V. and Clarke, V. (2006) 'Using thematic analysis in psychology', Qualitative Research in Psychology, 3(2), pp. 77-101.

Chan D.S.K. (2003) 'Validation of clinical learning inventory', West J Nurs Res, 25(5), pp. 519-532.

Dacre Pool, L., Qualter, P. and Sewell, P.J. (2014) 'Exploring the factor structure of the CareerEDGE employability development profile', Education+ Training, 56(4), pp. 303-313.

Entwistle, N. and Ramsden, P. (2015) Understanding student learning (Routledge Revivals). Oxon: Routledge. 
Hayes et al. Perception of academic learning environments and perceived impact on articulation of employability skills

Evetts, J. (2013) 'Professionalism: value and ideology', Current Sociology, 61(5-6), pp. 778-796.

Freeman, R., Millard, L., Brand, S. and Chapman, P. (2014) 'Student academic partners: student employment for collaborative learning and teaching development', Innovations in Education and Teaching International, 51(3), pp. 233-243.

Hayes, C. and Davies, M.S. (2014) 'A phenomenological evaluation of a hybrid model of problem based learning for multidisciplinary healthcare practitioners', Journal of Learning Development in Higher Education, Issue 7, June, pp. 1-21.

Herrington, J., Reeves, T.C. and Oliver, R. (2014) 'Authentic learning environments', in Spector, J.M., Merrill, M.D., Elen, J. and Bishop, M.J. (eds.) Handbook of research on educational communications and technology. $4^{\text {th }}$ edn. New York: Springer, pp. 401-412.

Hordern, J. (2014) 'Workforce development, higher education and productive systems', Journal of Education and Work, 27(4), pp. 409-431.

Jackson, D. (2015) 'Employability skill development in work-integrated learning: barriers and best practice', Studies in Higher Education, 40(2), pp. 350-367.

Lahman, M.K., Rodriguez, K.L., Moses, L., Griffin, K.M., Mendoza, B.M. and Yacoub, W. (2015) 'A Rose by any other name is still a Rose? Problematizing pseudonyms in research'. Qualitative Inquiry, 21(5), pp. 445-453, doi: 1077800415572391.

La Placa, V., McVey, D., MacGregor, E., Smith, A. and Scott, M. (2014) 'The contribution of qualitative research to the Healthy Foundations life-stage segmentation', Critical Public Health, 24(3), pp. 266-282.

Mahmood, L., Slabu, L., Randsley de Moura, G. and Hopthrow, T. (2014) 'Employability in the first degree: the role of work placements on students' perceptions of graduate employability', Psychology Teaching Review, 20(2), pp. 126-136. 
Mirghani, H.M., Ezimokhai, M., Shaban, S. and van Berkel, H.J. (2014) 'Superficial and deep learning approaches among medical students in an interdisciplinary integrated curriculum', Education for Health, 27(1), pp. 10-14.

Moos, R.H. (1980) 'Evaluating classroom learning environments', Studies in Educational Evaluation, 6(3), pp. 239-252.

Nagarajan, S.V. and Edwards, J. (2015) 'The role of universities, employers, graduates and professional associations in the development of professional skills of new graduates', Journal of Perspectives in Applied Academic Practice, 3(2), pp. 26-37.

Pegg, A., Waldock, J., Hendy-Isaac, S. and Lawton, R. (2012) Pedagogy for employability. York: The Higher Education Academy.

Pololi, L. and Price, J. (2000) 'Validation and use of an instrument to measure the learning environment as perceived by medical students', Teach Learn Med, 12(4), pp. 201207.

Prendergast, C. (2015) 'Professionalism and contracts in organizations', Journal of Labor Economics, 33(3 Part 1), pp. 591-621.

Ramsden, P. (1991) 'A performance indicator of teaching quality in higher education: the course experience questionnaire', Studies in Higher Education, 16(2), pp. 129-150.

Salmon, G. and Wright, P. (2014) 'Transforming future teaching through 'Carpe Diem' learning design', Education Sciences, 4(1), pp. 52-63.

Senior, C., Reddy, P. and Senior, R. (2014) 'The relationship between student employability and student engagement: working toward a more unified theory', Frontiers in Psychology, 5(March), p. 238.

Sharples, M., Adams, A., Ferguson, R., Gaved, M., McAndrew, P., Rienties, B. and Whitelock, D. (2014) Innovating pedagogy 2014. Milton Keynes: The Open University. 
Hayes et al. Perception of academic learning environments and perceived impact on articulation of employability skills

Thomas, G.P. and Anderson, D. (2014) 'Changing the metacognitive orientation of a classroom environment to enhance students' metacognition regarding chemistry learning', Learning Environments Research, 17(1), pp. 139-155.

Tymon, A. (2013) 'The student perspective on employability', Studies in Higher Education, 38(6), pp. 841-856.

Vygotsky, L.S. (1978) Mind in society: the development of higher psychological processes. Cambridge, MA: Harvard University Press.

Wellington, J. (2015) Educational research: contemporary issues and practical approaches. London: Bloomsbury Publishing.

\section{Author details}

Dr Catherine Hayes, Principal Lecturer in Learning and Teaching, Faculty of Applied Sciences, University of Sunderland.

Dr John Fulton, Principal Lecturer in Nursing, Faculty of Applied Sciences, University of Sunderland.

Dr Siobhan Devlin, Principal Lecturer in Learning and Teaching, Faculty of Applied Sciences, University of Sunderland.

Dr Diane Westwood, Principal Lecturer in Learning and Teaching, Faculty of Applied Sciences, University of Sunderland.

lain Garfield, Head of Estate Planning and Development, Newcastle University Management, Estates Department (formerly University of Sunderland).

Phil Beardmore, Accommodation Planner, Estates Department, University of Sunderland.

Dr David Archer, Senior Lecturer in Sport and Exercise Science, Faculty of Applied Sciences, University of Sunderland. 
Hayes et al. Perception of academic learning environments and perceived impact on articulation of employability skills

Dr Lewis Bingle, Senior Lecturer in Microbiology, University of Sunderland.

Michael Collins, Senior Lecturer in Clinical Skills, University of Sunderland. 